\author{
Journal of Research \& Health \\ Social Development \& Health Promotion \\ Research Center \\ Vol. 8, No. 1, Jan \& Feb 2018 \\ Pages: 61- 67 \\ DOI: 10.29252/acadpub.jrh.8.1.61 \\ Original Article
}

1. Correspondence to: Department of Health Education \& Health Promotion, School of Public Health, Zahedan University of Medical Sciences (ZUMS), Zahedan, Iran

Email: serajimaryam@gmail.com

2. Department of Health Education \& Health Promotion, School of Public Health, Shahid Beheshti University of Medical Sciences (SBMU), Tehran, Iran

Received: 29 Aug 2016 Accepted: 23 Jan 2017

How to cite this article: Seraji M, Rakhshani $M$. The effect of education on performance and awareness rate of hospitalized heart failure patients regarding their self-care behaviors and methods. J Research \& Health2018; 8(1): 61- 67 .

\section{Effect of education on practice and knowledge rate of hospitalized heart failure patients regarding their self-care behaviors and methods \\ Maryam Seraji ${ }^{1}$, Fatemeh Rakhshani ${ }^{2}$}

\begin{abstract}
Heart failure is one of the chronic conditions of heart in the elderly people. The current study aimed to determine the effects of education on knowledge and practice of hospitalized heart failure patients regarding their self-care behaviors. This was a quasi-experimental study with control group which was conducted on 140 patients hospitalizing in Zahedan. The primary information was gathered through a questionnaire and an interview. Then the intervention group was given an educational package including booklet, educational compact disc, and Bluetooth films and posttest was performed after one month. The study's findings indicated that the mean score of patients' knowledge in intervention group before and after education was $8.23 \pm 3.79$ and $21.93 \pm 2.32$ respectively and the mean score of knowledge changes in intervention group was $13.78 \pm 4.27$. Moreover, the mean score of patients' practice in intervention group before and after the education was $39.40 \pm 5.49$ and 66.04 \pm 3.44 respectively and the mean score of practice changes in intervention group was $26.57 \pm 3.37$. The current study revealed the provided education for affected patients by congestive heart failure can enhance knowledge of the disease, improve their practice and self acre behaviors, promote their health condition, and decrease the patients' death rate.
\end{abstract}

Keywords: Knowledge, Education, Heart Failure, Practice, SelfCare

\section{Introduction}

Cardiovascular diseases are the most relevant causes of mortality in the world and they are known as the main reasons of disability [1]. In the earlier years of 21 st century, cardiovascular diseases were responsible for half of the deaths in developed countries and $25 \%$ of all deaths in developing countries.

The death rate resulting from cardiovascular diseases is rapidly increasing in Middle East countries, and they are known as the main causes of death in this area (25 to $45 \%$ of all deaths) [1]. In these countries, the main reason for increasing rate of deaths resulting from cardiovascular diseases which is the changes taking place in people's economical status and life style and consequently leads to high 
prevalence of factors creating cardiovascular diseases [1].

According to the reported statistics of Vice Chancellor for Health, the rate of daily deaths due to cardiovascular diseases in Iran was 369 cases during the year 2003 [2]. After being cured, most of these cardiovascular diseases will change to a disease known as congestive heart failure [3]. Congestive heart failure is a pathophysiologic status in which cardiac output is not able to provide oxygen or nutrition for body tissues [4]. In fact, Congestive Heart Failure (CHF) is a complicated clinical syndrome having various reasons in which a functional failure will lead to heart disorder, so that it cannot perform naturally. Therefore, a person who suffering from these problems will have symptoms such as weakness, fatigue, and asthma [5]. The final phase of cardiovascular diseases is congestive heart failure [6].

Among various and important dimensions of CHF, we can mention some including the increasing rate of this disease incidence in different societies, the high frequency of ischemic heart diseases (IHD), the high rate of deaths and short lifetime in patients with $\mathrm{CHF}$, and re-hospitalization with high costs [7]. Furthermore, some studies showed that at least $50 \%$ of heart failure patients do not follow their treatment recommendations, and this issue leads to re-hospitalization of patients and their affection to the complications of heart failure [8]. The incidence rate of this disease is increasing with aging, and its prevalence rate is also growing rapidly in societies with more aged people. According to the results of USA heart Association published in 2009, nearly 2\% of the country's population is suffering from congestive heart failure [9].

One of the best methods of preventing the incidence, progression, and occurrence of the disease complications is to educate patients about self-care behaviors [10]. Self-care is one of the most significant aspects of treatment in patients affected by CHF (2). Congestive heart failure is one of the most prevalent factors leading to the patient's re-hospitalization after 60 days of discharge [11]. Most of the studies stated that nearly $50 \%$ of the patients who had received treatment will refer to the hospital and be hospitalized because CHF (9). Heart failure is the most extensive cause of hospitalization in a hospital [12]. The main symptoms for the patient's referring to the hospital were asthma and inflammation resulting from daily activities, and $59 \%$ of the re-hospitalization was because of Sodium use and high volume of water in body [9]. Self-care behaviors have significant in congestive heart failure because most of the patients' health care is taken without the supervision of medical team [13]. In patients affected by chronic diseases, following the self-care behaviors is very essential and vital. By learning the required skills in this regard, patients can directly affect their own welfare, function, practice, and disease procedure [3]

Most of the causes and factors which deteriorate heart failure can be prevented by educational interventions and learning how to handle the chronic conditions of a disease. These issues form the main skeleton of selfcare [14]. Studies showed that strategies focusing on educational needs of patients themselves were more successful than those provided by others [15]. Improving the patient's knowledge level through self-care education reduced their turning back to hospital specialty to the Cardiac Care Unit (CCU) and cardiology section [16]. Patient's cooperation in treatment and self-care programs another important issue in promoting the treatment quality. Therefore, Patients' unawareness of the self-care methods regarding treatment programs will result in negative aftermaths for them [17].

Poor or weak self-care behaviors including lack of following the medicine and food diet can lead to 20 to $60 \%$ increase in rehospitalization [17]. Self-care behaviors are important aspects of treatment and the base for heart failure management. They include behaviors such as following a low-salt diet, medicine diet and etc. in order to keep the body healthy, physiologically [18]. As the self-care behaviors in this disease, we can 
mention the following cases as some important examples: daily weighting or scaling, following a special food and medicine diet, regular physical activities, not smoking, contacting the doctor if observing inflammation in feet, ankle, shin, or stomach, measuring daily urination rate, and not drinking too much liquid [15]. Daryabeigi conducted a study in 2004 and reported that education had a positive effect on enhancing the patients' self-care knowledge and also it was stated that education can influence self-care behaviors positively [10]. Therefore, informing people and making them aware of the disease and risk-creating factors of the disease are considered as the base of education and the main goals in this regard are providing information, changing the attitudes, and changing the behaviors which cause to control the disease and promote the disease's preventive behaviors [1].

The current study aimed to determine the effects of education on knowledge and practice of hospitalized heart failure patients regarding their self-care behaviors in Zahedan hospitals

\section{Method}

This is quasi-experimental study with a control group which was conducted on 140 patients affected by heart failure who were hospitalized in cardiology and CCU sections of Khatam-alanbia and Ali-ebn-abitaleb hospital in Zahedan, (the east of Iran), 2013. The patients were put in two different groups, an intervention group (70 patients) and a control group (70 patients). In order to prevent the effects of different treatments in the two hospitals, 35 patients were chosen from Ali-ebn-abitaleb and 35 patients from Khatam-al-anbia hospital. When the intervention group was being selected in one hospital, in another one the control group was being chosen simultaneously. The inclusion criteria were: 1) heart failure diagnosis by a cardiologist and passing of four months after the diagnosis, 2) having an echocardiography in patient's case and having an ejection fraction rate lower than $40 \%, 3$ ) hospitalized was patients in CCU and post CCU sections, 4) The patient's required cooperation during the study phase.

These control group patients received the required education. But during the whole study phase they received no provided educations by the researchers. Moreover, they were taken both preest and post-test and the data was analyzed by comparing the results of intervention group. However, due to ethical issues, the patients in the control group were given the required education as well after study. With the confidence interval of $95 \%$, and the statistical power of $80 \%$ for the difference of self-care scores before and after the education, we conducted the current study based on the previous studies and at first, the estimated number was 53 patients but due to deletion possibility, we increase the number to 70 patients in each group. The nonprobability and convenience sampling method was used for choosing the participants. That is, the hospitalized patients affected by CHF were recognized and interviewed with daily referring to treatment centers. The patients who were studied before were omitted in the next days of the study. Moreover, in order to prevent bias in the study (the effects of various treatments in two hospitals), the case and control groups were selected from the two hospitals. That is, we selected 35 samples for case and 35 samples for control group from Khatam-al-anbia hospital and 35 samples for case and 35 samples for control group from Ali-ebn-abitaleb hospital.

After considering the patients regarding their inclusion criteria and their willingness to take part in the study, the pretest questionnaire was completed by a trained researcher. The required information about study, its objectives and duration were provided by the researcher, preferably during the last days of patients' hospitalization (when they felt better physically and emotionally and were ready to receive the required education) and in a face-to-face manner. Moreover, it should be mentioned that the usual education was also provided for both groups by section's nurses. In addition, parallelism into groups was carried out for each individual and based on 
variables such as age, gender, and educational level.

There were two educational sessions. The first session was about the booklet content, through a 45 minutes speech and a Bluetooth film; then an educational compact disc (CD) which aimed at enhancing the patients' knowledge, attitude, and practice regarding their self-care behaviors was given to the patients. In the second session which was held the day after the first session; some questions were raised about both the content and topics of the educational $\mathrm{CD}$ and booklet. Finally, the information was summarized and collected by the researcher, and with regard to the incorrect points, some elaborations were provided. After one month, the post-test phase of the study for intervention group was conducted by referring to their home. In this study, the data was gathered through a questionnaire which was completed during the interview phase by a trained researcher.

Since there was no standard questionnaire in this regard, the researchers made questionnaire was used through different books and references as well as the results of some other studies in order to develop the primary questionnaire. Then, in order to determine clarity of the questions, the questionnaire was given to $15 \mathrm{CHF}$ hospitalized patients in Khatam-al-anbia hospital and they were asked through an interview to express any possible vagueness or ambiguity presented in the questions. Therefore, the required changes were made clarification based on the received comments and suggestions.

Furthermore, in order to determine the questionnaire's face and content validity, it was given to 10 experts in health education and cardiovascular diseases. After the required rectifications, the questionnaire's content validity ratio (CVR) became 0.71 and its content validity index (CVI) became 0.81 . Internal consistency was used to determine the questionnaire's reliability and test re-test method was used for its stability.

That is, the first test was carried out on 30 hospitalized patients in CCU section and they were not entered in the final study. After 15 days, the test was repeated and the questionnaire was filled in again by the same group. Then, by the use of Pearson correlation test, the difference between first and second set of responses was determined. Questions with correlation coefficient with less than 0.7 were deleted. Finally, the mean score of Cronbach's alpha for questions on knowledge and self-care behavior in the final questionnaire was 0.81 and 0.81 and the correlation coefficient was 0.77 and 0.86 respectively.

The questionnaire had two parts: demographic information of the heart failure patients (9 questions), and questions on knowledge of self-care behaviors (13 questions). The correct response had three points, "do not know" response had two points, and incorrect response had one point. If the patient chooses "do not know" response, he/she has better conditions for receiving education; but if a person chooses the incorrect response, first that incorrect information must be removed and rectified, then the correct knowledge be provided to individual. (The score range was 13 to 39). There were 16 questions on practice regarding self-care behaviors which had five choices (always, often, sometimes, rarely, and never) and the score range was 16 to 80 .

\section{Results}

In the current study, 140 heart failure patients were studied in 2 groups: an intervention group and control group. The patients' mean age was $60.79 \pm 12.17$ years old. As shown in Table 1, majority of the patients were above 60 years old, most of them were men (68.6\%), married $(75.8 \%)$, and illiterate (47.1\%). Moreover, regarding the background and demographic variables, there was no statistically significant difference between intervention and control group (Table 1).

The results of paired t-test as Table 2, showed that regarding the knowledge mean of selfcare behaviors in patients with heart failure, there was a statistically significant difference between pretest and posttest education in intervention group $(p<0.001)$. Moreover, this was the case in control group as well $(\mathrm{p}<0.0001)$. 
Education on self-care behaviors in heart failure

Table 1 Demographic and background features of heart failure patients in intervention and control group

\begin{tabular}{|c|c|c|c|c|}
\hline & & & & \\
\hline & ariable & Intervention & Control & $\mathrm{p}$ \\
\hline & Male & $42(60.0)$ & $48(68.6)$ & \\
\hline Чсласе & Female & $28(40.0)$ & $22(31.4)$ & 0.21 \\
\hline & Married & $51(72.9)$ & $53(75.7)$ & \\
\hline Marital status & Widow & $19(27.1)$ & $14(20.0)$ & 0.58 \\
\hline & Divorced & $0(0.0)$ & $3(4.3)$ & \\
\hline & Housewife & $29(41.4)$ & $31(44.3)$ & \\
\hline Jal & Worker-farmer & $18(25.7)$ & $12(17.1)$ & \\
\hline J00 & Employee-retired & $16(22.9)$ & $11(15.7)$ & 0.50 \\
\hline & Self - employed & $7(10.0)$ & $16(22.9)$ & \\
\hline & illiterate & $47(67.1)$ & $47(67.1)$ & \\
\hline Education & $\begin{array}{l}\text { Elementary, } \\
\text { secondary school }\end{array}$ & $14(20.0)$ & $15(21.4)$ & 0.70 \\
\hline & Diploma and higher & $9(12.9)$ & $8(11.4)$ & \\
\hline & Hypertension & $52(74.9)$ & $52(74.9)$ & \\
\hline & Diabetes & $37(52.9)$ & $27(38.6)$ & \\
\hline $\begin{array}{l}\text { Background } \\
\text { diseases }\end{array}$ & Heart attack & $34(48.6)$ & $47(67.1)$ & 0.38 \\
\hline & Pulmonary disease & $24(34.3)$ & $17(24.3)$ & \\
\hline & digestive disorders & $14(20.0)$ & $24(34.3)$ & \\
\hline & No hospitalization & $3(4.3)$ & $1(1.4)$ & \\
\hline & One hospitalization & $9(12.9)$ & $16(22.9)$ & \\
\hline experience & Two hospitalizations & $20(28.6)$ & $14(20.0)$ & 0.24 \\
\hline & $\begin{array}{l}\text { More than two } \\
\text { hospitalizations }\end{array}$ & $38(54.3)$ & $39(55.7)$ & \\
\hline
\end{tabular}

Table 2 Comparing the mean and standard deviation of awareness score in the HF patients'self care behaviors before and after education in both intervention and control group

\begin{tabular}{|c|c|c|c|c|c|c|}
\hline & \multicolumn{2}{|c|}{ Knowledge } & \multirow{2}{*}{$\mathrm{p}$} & \multicolumn{2}{|c|}{ Practice } & \multirow{2}{*}{$\mathrm{p}$} \\
\hline & Pre-intervention & Post-intervention & & Pre-intervention & Post-intervention & \\
\hline Intervention & $8.23 \pm 3.79$ & $21.93 \pm 2.32$ & $<0.001$ & $39.40 \pm 5.49$ & $66.04 \pm 3.44$ & $<0.001$ \\
\hline Control & $8.08 \pm 3.27$ & $10.10 \pm 2.03$ & $<0.001$ & $43.17 \pm 6.59$ & $45.33 \pm 3.64$ & \\
\hline $\mathrm{p}$ & $<0.79$ & $<0.001$ & & $<0.001$ & $<0.001$ & $<0.019$ \\
\hline
\end{tabular}

Moreover, in Table 2, the statistical paired t-test revealed that difference in mean scores of patients' practice before and after the intervention was statistically significant in both intervention and control groups $(p<0.001)$. In addition, independent t-test showed that the difference in mean scores of practice in both intervention and control groups was statistically significant $(p<0.001)$. This difference in intervention group (63.4\%) was positive and higher than in control group (5.4\%); this issue indicates that education can improve practice of self-care behaviors in intervention group.

\section{Discussion}

In the current study, it was revealed that educating the congestive heart failure patients can improve their knowledge of selfcare behaviors and promote their practice regarding the self care behaviors. In 2005, Smith carried out a study about the effects of education via videos on heart failure patients [20]. His study's results were consistent with our findings. However, in a study conducted by Sajedi, patients were not highly aware of their food and medicine diet [7] and the results didn't match to our study's findings. 
In addition, another study was carried out by Daryabeigi in 2004 and the results indicated that education had positive influence on improving the participants' self-care knowledge and their self-care behaviors [10]. His study's findings were consistent with the current study's results. In this study, the scores of knowledge in intervention group increased significantly in comparison with the scores of pre-intervention phase and the scores of control group. This fact indicates the considerable effects of education on patients; moreover, the mean differences in intervention group are higher than that in control group. This issue is related to the designed educational package given to the intervention group. Of course, at the end of the study phase, the mean score of control group was significantly higher than their scores in pre-study phase, but not as high as the mean score of intervention group. It seems that this increase is mostly related to the routine educations provided by nurses in the sections and the patients' regular hospitalizations. Moreover, Hanive also stated that educating the patients is a key factor in curing the heart failure patients. In his studies, it was reported that the highest increase in knowledge and knowledge was observed in patients who had experienced hospitalizations before, and the patient with a longer heart failure disease had more knowledge and knowledge than those with a shorter period of congestive heart failure [18]. Results of the current study revealed that patients' practice in following the selfcare behaviors improved considerably after receiving the education. In a study conducted by Louei in 2008, the results revealed that before receiving any intervention, there was no statistically significant difference between the mean of life quality and self-care behaviors in both intervention and control group. However, after intervention, a statistically significant difference was reported between the two groups regarding those variables $(p<0.001)$. The current study revealed that the high mean of quality of life and self-care behaviors in intervention group rather than control group is because of the implementation of self-care educational programs. It can be said that this study indicated that self-care education is very effective and practical in promoting self-care behaviors in patients affected by Congestive heart failure [19]. In addition, in a quasi-experimental study carried out by Jaresmal et al. in 1999, the effects of education and support on selfcare and quality of life of CHF patients were taken into consideration. The patients were put into two groups: a control group receiving some general cares and an intervention group received educational-supportive intervention. As a result, the patients' self-care abilities were not changed by the intervention, but the self-care behaviors in intervention group were improve in comparison with the control group [21]. These findings are consistent with the results of the present study. In the current study, the patients' knowledge and practice scores in intervention group were significantly higher than the scores in pre-intervention phase and the control group's scores. These observations indicate the positive effects of education on these patients.

The limitations of this study included: Some patients were unable to participate due to their old age. Also, some of the patients did not have cell phone to receive educational videos by Bluetooth.

\section{Conclusion}

Since self-care behaviors in heart failure patients are of high significance so interventional attempts to promote these behaviors and practices in these patients are very essential and vital. Results of the current study revealed that educating the patients about self-care behaviors, and designing an educational package for a group of patients will increase the patients' knowledge; subsequently their practice and self-care behaviors would improve as well. Therefore, it is necessary to design and implement educational programs in order to promote the patients' knowledge of the disease's etiology, the correct treatment methods, and the correct self-care behaviors and practices due to the significance of knowledge as an important factor in heart failure patients' self-care behaviors. 


\section{Acknowledgments}

The present study is extracted from an MA thesis. We would also like to show our gratitude to the vice chancellor for research and information technology of Zahedan university of medical sciences that provided the required finance for implementation of this research.

\section{Contribution}

Study design: SM, RF

Data collection and analysis: SM

Manuscript preparation: SM, RF

\section{Conflict of Interest}

"The authors declare that they have no competing interests."

\section{Funding}

This work was supported financially by vicechancellery of research and technology of Zahedan University of Medical Sciences.

\section{References}

1- Jalalian R, Maleki M, Azizi F, Janghorbani M, Hatami H. Epidemiology and control of common illnesses in Iran. Third Edition. Tehran: Khosravi; 2012. pp: 11-36.

2- Shoja Fard J, Naderian H, Baghiani Moghadam MH, Mazlumi MAS, Sanati H, Askarshahi M. Considering the effects of education on self-care behaviors, advantages and obstacles in doing it for patients affected by heart failure in Tehran. Journal of Paramedical Science2008; 2(4): 43-55. 3-Ahrari Sh, Heidari A, Vaghei S. The role of compatibility pattern on the food diet of patients with heart failure. Ofogh-e-Danesh2010; 17(4): 18-24.

4- Bonow RO, Mann DL, Zipes DP, Libby P. Braunwald's heart disease: a textbook of cardiovascular medicine. Philadelphia, Pennsylvania, US: Saunders; 2001

5- Azizi F, Hatami H, Janghorbani M. Epidemiology of diabet. In: Azizi F, Hatami H, Janghorbani M, eds. Epidemiology and control of common disorders in Iran. 2nd ed.Tehran: Eshtiagh; 2000. pp: 32-8.

6- Jaarsma T، Halfens R, Tan F, Abu-Saad HH, Dracup K, Diederiks J. Self-care and quality of life in patients with advanced heart failure: the effect of a supportive educational intervention. Heart Lung2000; 29(5): 319-30.

7- Harrison A. Basics of internal medicine. Tehran:Teimoorzadeh; 2002.
8- Seraji M, Tabatabaie P, Rakhshani F, Shahrakipor M. The effect of educating self-care behaviors to patients with heart failure in hospitals of Zahedan. Journal Health Scope2013; 2(1): 104-9.

9- Huyen NN, Jullamate P, Kangchai W. Factors related to self-care behaviors among older adults with heart failure in thai Nguyen general hospital, Vietnam. The first international conference on interdisciplinary research and development, 31 May - 1 June 2011.

10- Marvin HM. Diseases of the Heart and Blood Vessels: Nomenclature and Criteria for Diagnosis. Arch Intern Med1964; 113(6): 906-7.

11- Dickson VV, Buck H, Riegel B. A qualitative metaanalysis of heart failure self-care practices among individuals with multiple comorbid conditions. J Card Fail2011; 17(5): 413-9.

12- Hassan M. Readmission of patient to hospital: still ill defined and poorly understood. Int J Qual Health Care2001; 13(3): 177-9.

13- Mohseni M. The fundamentals of health education. Third edition. Tehran, Tahuri; 2003.

14- Safari M, Shojaeezadeh D, Ghofrani Pour F, Heidarnia A. Theories, models, and methods of health education and health promotion. Tehran, Asar Sobhan; 2009.

15- Malek Alaee M. Radolph cardiovascular diseases. Harrison. Translation of internal medicine principles. Tehran: Nasl farad; 2005.

16- Butman SM, Ewy GA, Standen JR, Kern KB, Hahn E. Bedside cardiovascular examination in patients with severe chronic heart failure: importance of rest or inducible jugular venous distension. $J$ Am Coll Cardiol1993; 22(4): 968-74.

17- Stevenson LW, Perloff JK. The limited reliability of physical signs for estimating hemodynamics in chronic heart failure. JAMA Cardiol1989; 261(6): 884-8.

18-Alam M, Rosenhamer G, Hoglund C. Comparability of echocardiography and chest X-ray: following myocardial infraction. Journal International Medicine1989; 226(3): 171-5.

19- Silver MA, Cianci P, Pisano CL. Outpatient management of heart failure - program development and experience in clinical practice. IIinois: The heart failure institute and heart Failure Center; 2004.

20- Smith CE, Koehler J, Moore JM, Blanchard E, Ellerbeck E. Testing videotape education for heart failure. Clin Nurs Res2005; 14(2):191-205.

21- Jaarsma T, Halfens R, Huijer Abu-Saad H, et al. Effects of education \& support on self-care \& resource utilization in patient with heart failure. Eur Heart J1999; 20(9): 673-82.

\footnotetext{
Copyright $\odot 2016$ ASP Ins. This open-access article is published under the terms of the Creative Commons Attribution-NonCommercial 4.0 International License which permits Share (copy and redistribute the material in any medium or format) and Adapt (remix, transform, and build upon the material) under the Attribution-NonCommercial terms.
} 